TABLE D.-8 Cases in which the Capsule of the Lens was Left Behind, oving to Bursting at the Time of Operation.

\begin{tabular}{|c|c|c|c|c|c|}
\hline 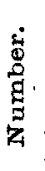 & Name. & 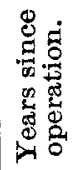 & 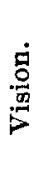 & 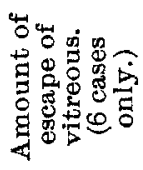 & $\begin{array}{l}\text { Remarks at time of } \\
\text { operation. } \\
\text { (Notes in brackets.) }\end{array}$ \\
\hline 1 & Akro. & $6 \mathrm{~ms}$. & $\frac{6}{5}$ & - & $\begin{array}{l}\text { (Capsule needled pre- } \\
\text { viously.) }\end{array}$ \\
\hline 2 & Ahmad Khan. & $1 \frac{1}{2}$ & $\frac{6}{6}$ & Drop. & No iridectomy. \\
\hline 3 & Nihala. & $4 \frac{1}{2}$ & $\frac{6}{8}$ & - & 一 \\
\hline 4 & Natha. & 5 & $\frac{6}{10}$ & Drop. & - \\
\hline 5 & Ahmed. & 6 & * & " & $\begin{array}{l}\text { Drop of vitreous taken } \\
\text { out of right eye on } \\
\text { account of tension. }\end{array}$ \\
\hline 6 & Diwan Singh. & 2 & $x^{6} \varepsilon$ & " & Iridectomy. \\
\hline 7 & Gaunsa. & 6 & $\mathbf{3} \sigma$ & $"$ & No iridectomy. \\
\hline 8 & Shib Dial. & 1 & $\dagger$ & Some. & $\begin{array}{l}\text { Iridect om y. (Dense } \\
\text { after-cataract seen.) }\end{array}$ \\
\hline
\end{tabular}

* Not noted by error. $\quad$ i Counts fingers only at 2 yards.

TABLE E.-Detailed Notes on 8 Cases (7 Patients, 1 Double) with Diseased Condition of the Fundus.

CASE 1.-Name, B-. Operated on one and a half years ago. "Drop" of escape of vitreous in both eyes -both extracted on spoon. Vision $=6$. States that he had very poor vision in both eyes before cataract developed. Had syphilis. On ophthalmoscopic examination signs of old neuro-retinitis.

CASE 2.-Name, Para Singh. Operated on five years ago. Vision : Can only count fingers. Sight was all right for two years after operation. Then had high fever with delirium. Pupillary reaction very sluggish. Disc pale. Retina atrophied, probably caused by malarial optic neuritis.

CASE 3.-Name, Utman Dai. Operated on one year ago. Vision : Can only see hand movements. Both lenses well extracted in the capsule with a "drop" of escape in the right. Disseminated choroiditis seen in both eres on ophthalmo pic

CASE 4.-Name, Edoo. Operated on five years ago. Trace of escape CASE 4.- Name, Edoo. Operated on five years ago. Trace of escape of vitreous in right eye. Left eye lost previously from trachoma. Vision $={ }_{15}^{6}$. Very stupid old man. Could give no clear history of his condition. Retina presents appearance of retinitis pigmentosa sine pigmento in an early stage.

CASE 5.-Name, Ram Singh. Operated on one and a balf years ago. "The right lens is noted as having been previously dislocated by the "rawal" or lens coucher at the time of operation. It was noted also as having been expelled on completion of the incision with a "drop" of vitreous. Note made "bad patient." Vision $={ }_{6}^{6}$. On ophthalmoscopic examination the typical condition of retinitis pigmentosa sine pigmento, which always follows couching of the lens.

CASE 6.-Name, Hako. Operated on two years ago. Vision : Nil. Drop of escape in the left eye. Lens noted as dislocated at the time of operation. The same fundus condition as in Case 5 , but more advanced. CASE 7.-Name, Khuda Bux. Age 60 years. Operated on four and a half years ago. Escape of vitreous in one eye only, amount not noted. Both lens extracted in the capsule. Primary optic atrophy in both eyes.

\section{A REPORT OF SOME CASES OF VENOUS AN\&STHESIA.}

By C. M. PAGE, M.B., M.S. LoND., F.R.C.S. ENG., SURGICAI REGISTRAR, ST. THOMAS'S HOSPITAL;

AND

S. G. MacDONALD, M.A., M.B., B.C. Cantab., F.R.C.S. ENG.

LATE HOUSE SURGEON, ST. THOMAS'S HOSPIXAI.

Professor Bier, in April, 1908, read a paper at the German Surgical Congress entitled "On a New Method of Producing Anxsthesia in the Extremities." The procedure is applicable to either extremity, any part of which can be shut off from the general vascular system. The method consists essentially in the introduction of an anæsthetising fluid into one of the superficial veins of a given area of a linb, which area has previously been depleted of blood and isolated by tourniquets. The whole of the tissues of the isolated area are in this way infiltrated by exudation of the medium from the capillaries of that area. The cases recorded by Professor Bier were chiefly operations on the upper extremity, only one case of amputation of the leg having been performed. We have employed the method for nine operations, seven of these being major amputations and most of them cases in which general anæsthesia was considered inadvisable.

The details of the technique are as follows: the skin is prepared in the usual manner; a sterilised Esmarch's bandage is then firmly bound round the limb, from the periphery upwards, as high as the upper limit of the operation area. Above this, and in contact with its last turn, is placed another rubber bandage, sufficiently tight to check the arterial circulation. The bandage covering the distal part of the limb is now removed, and a third bandage is wound firmly round the extremity at the lower limit of the operation area. This bandage must be tight enough to prevent diffusion of the injected fluid into the distal part of the limb. After a preliminary skin infiltration an incision a couple of inches in length is made across the line of the vein chosen in the leg, usually the internal saphenous. (This incision may be made at any convenient level, though Professor Bier advises that the vein be picked up in the upper part of the operation area.) The vein is isolated and a cannula tied into it firmly, as for an intravenous infusion. The cannula should be directed centripetally if the vein be opened low down in the operation area, centrifugally if opened high up. Any small vessels that may have been divided are now secured to prevent leakage, and a good syringe of about 100 cubic centimetres capacity is attached by a short piece of pressure tubing to the cannula. The fluid is then injected gradually, a varying but considerable amount of pressure being required. As infiltration occurs the area swells and turns dusky white in colour. Complete anæsthesia of the isolated area appears in from five to 15 minutes from the commencement of the injection. It may be accelerated by gentle massage of the part to facilitate diffusion of the fluid, or, if necessary, by the injection of more fluid. When anæsthesia is complete the cannula is removed and the vein is tied off. The skin incision, unless it falls into line with the operation incision, is sutured, and operative measures are then proceeded with.

This anæsthesia of the infiltrated area Bier terms "direct anæsthesia." After 15 to 30 minutes, however, from the time of injection the rest of the limb below the isolated area also becomes anæsthetic. This he terms "indirect anæsthesia." It is due to the establishment of a "block" in the nerve trunks as they pass through the infiltrated area. Indirect anæsthesia, however, seems to be of limited practical value, on account of the uncertainty of the time required for its completion. At the termination of the operation the upper bandage is slowly removed in order that vessels divided during the operation may be secured. If more than ten minutes be required for suturing the wound this bandage should be replaced, as sensation returns in the infiltrated area in eight to ten minutes after its circulation is reestablished.

Should an infective focus exist in the lower part of the limb to be operated upon it would obviously be inadvisable to bandage the whole extremity. In such a case the limb is first elevated, and then the first Esmarch bandage is placed entirely above the septic focus, extending centripetally from the lower level of the operation area. The hæmostatic bandage is next applied at the npper limit of the operation area, and, before removing the first Esmarch bandage, a third bandage is applied at the lower limit of the operation area. If the latter proceeding be omitted blood will regurgitate from below into the area to be infiltrated, and imperfect anæsthesia will result. It is of the utmost importance that the vessels in the operation area be completely emptied before the injection be commerced. With regard to the incision for finding a vein, it is obviously better in amputations either to make this in the lower part of the isolated area, or to make it in such a position that it will fall into line with the amputation incision.

A limit to the extent of the tissues which can be infiltrated is set by the undesirability of injecting more than a certain quantity of the anæsthetising fluid ; 200 cubic centimetres of a 0.5 per cent. novocaine solution (which may be regarded as a maximum dose) should suffice to anæsthetise the field for most set operations; the area cannot conveniently be increased once operative procedures have commenced. As anæsthetic Bier recommends "novocaine" on account of its relative non-toxicity. A 0.5 per cent. solution in normal saline gives reliable results. We have used a 0.25 per cent. solution successfully in one case, though anæsthesia was somewhat more slowly produced. The amount injected varies with the size of the limb and the extent of the area to be infiltrated. From 50 to 75 cubic centimetres suffices for a moderate-sized elbow, while 150 cubic centimetres are required for a knee area. More can 
safely be employed in amputation cases, as only a small amount will subsequently reach the general circulation.

CaSE 1.-A male, aged 60 vears, was admitted to hospital on Jan. 27th, pletely encircled the right leg in its lower half. The ulcer was foul, the flbula was in part bare, and the limb was odematous as far as the kneejoint. The patient was suffering from profound anæmia and toxæmia. The vessels were much thickened, and the heart was weak and irregular. There was no albuminuria or glycosuria. On Feb. 2nd the leg was 120 cubic centimetres of 0.5 per cent novocaine were used; absolute anæsthesia was obtained; there was no evidence of shock, the pulse-rate before and after amputation being 88 . The after-history was uneventful ; suppuration occurred, however, so stitches were removed and the wound was allowed to heal by granulation. No necrosis of bone occurred, and the wound was soundly healed by April 19th, on which day the patient, having been provided with a knee-rest, left the day the

CASE 2.-A female, aged 45 years, was admitted to hospital on Jan. 26th, 1909, with moist gangrene of the third toe of the left foot. It had commenced in a slight injury sustained four months previously. On admission there was cellulitis extending on to the foot. Both leg. were cedematous. There were no sensory changes nor vascular disease. The urine contained a trace of albumin; no sugar was found while th patient was in the hospital, though it was stated to have been present in the out-patient room. Amputation of the toe at the metatarsoanæsthesia. 50 cubic centimetres of a 0.5 per cent. solution of novocain was used. The operation was commenced ten minutes after infiltra tion; the patient felt the skin incision, although it did not evoke pain. Owing to the condition of the tissues the wound was left open. Vomiting occurred once 12 hours after the operation; apart from this recovery was uneventful, and the patient was discharged on Feb. 22nd, the wound having completely healed. The incompleteness of the anæsthesia in this case confirms Professor Bier's observation that probably results from the difficulty in completely depleting these areas of blood

CASE 3.-A male, aged 76 years, was admitted to hospital on Feb. 1st, 1909, for senile gangrene of the left foot, which had commenced a for night before. The patient had suffered from polyuria and wasting for viously. On admission the first, third, and fourth toes of the left foot were in a state of dry gangrene; pulsation could be felt in the popliteal were in a state of dry gangrene; pulsation could be felt in the popliteal The urine averaged 75 ounces daily and contained albumin and sugar. The urine averaged 75 ounces daily and contained albumin and sugar. 700 grains. In spite of rest, \&c., the gangrenous process began to 700 grains. In spite of rest, \&c., the gangrenous process began to amputation was performed at the lower third of the thigh, venous anæsthesia being used. The septic condirion of the foot made it necessary to apply the Fsmarch bandage entirely above the gangrenou area. 100 cubic centimetres of a 05 per cent. solution of novocaine wer injected. The pulse rose from 96 to 122 ; the patient sweated and in the operation area, and the rise in the pulse-rate was apparently due in the operation area, and the rise in the pulse-rate was apparently due to the fact that some novocaine had reached the general circulation. The tourniquet was therefore reapplied, and, as anæsthesia was as yet The patient now complained of much pain in his toes, so he was given chloroform inhalation (one drachm in all being used) for the skin incision. Consciousness rapidly returned, but there was no further rise of the pulse-rate, and no evidence that he experienced pain during the division of nerves or bone. Unfortunately the patient's heart began to fail on Feb. 10th and he died on the 14th.

Necropsy.-The lungs were congested and codematous. The heart was hypertrophied; the myocardium was unduly soft, and there were atheromatous patches, and all the valve. The arom-sized vessels were rigid and calcified. The head of the pancreas was unduly hard. Microscopy showed fatty infiltration; the islands of Langerhans were scarce. The kidneys were moderately granular. The brain showed no gross lesion to account for the old hemiplegia, but the lumen of the left middle cerebral artery was much diminished. Examination of the amputation stump showed no attempt at repair. The artery was rigid and calcareous, and no clot was present above the ligature.

In this case the rigidity of the artery accounts for the difficulty experienced in emptying the operation area of blood. In the production of the pain there were probably two factors. Firstly, owing to the septic condition of the foot, the Esmarch bandage had to be applied entirely above it ; the result of this was venous congestion of the foot. Secondly, owing to the rigid condition of the vessels, more pressure than usual had to be applied to produce hæmostasis.

CASE 4.-A male, aged 43 years, was admitted to hospital on Jan. 11th, 1909, for chronic synovitis of the right knee of two Feb. 15th the joint was explored by Mr. C. A. Ballance, venous anæs thesia being used. 100 cubic centimetres of a 0.5 per cent. novocaine
solution were injected into the internal saphenous vein, perfect anæesthesia being obtained in five minutes. The synovial membrane of the subcrureal pouch, and that on either side of the patella, was found to be studded with tuberculous nodules (verified by the microscope). The diseased synovial membrane was therefore removed. On account of considerable oozing into the joint cavity the latter was drained for 48 hours. The pulse-rate at the beginning of the operation was 90. Two hoars later it increased to 100 and became irregular, but had again dropped to 90 in 12 hours. In 48 hours the pulse, though regular, was weak. Subsequently some superficial suppuration occurred. The wound had healed by March $23 r$, on which day the

CASE 5.-A male, aged 44 years, was anmitted to hospital on Feb. 14th, 1909, with an ununited fracture of the tibia and the fibula. portion of the tibia betw compound fracture six months previously; necrosed and come away. The patient was an alcoholic subject; there was no attemnt at new bone formation; the foot was cedematous and paritul, and there was a large pressure sore on the heel. Amputation
below the seat of election was performed on Feb. 20th, 1909, venous anæsthesia being used. 120 cubic centimetres of 0.5 per cent. novocaine solution were injected into the internal saphenous vein ; the tourniquet caused some slight discomfort which rapidly disappeared as anæsthesia became established. There was no alteration in the pulse-rate during the operation, but in this case some cardiac irregularity appeared on the fourth day. The wound healed per primam, the patior
provided with a knee-rest, and left the hospital on March 12th.

CASF 6. - A female, aged 39 years, was admitted to hospital on Feb. 6th, 1909, for diabetic gangrene of the left foot of six weeks' duration. The foot was red, oedematous, and covered by numerous organised and the corresponding metatarsal bones and phalanges were exposed. Before admission the foot had been treated with hot carbolic dressings; cellulitis had spread to the lower third of the leg, and the skin up to this level was red, oedematous, and covered with vesicles; skin up to this level was red, oedematous, and covered with vesicles;
the upper limit of the inflammation was sharply defined, and corresponded to the level of the dressing. The patient could move her toes. but sensation was impaired, and there was considerable pain. The but sensation was impaired, and there was considerable pain. The
vessels were thickened beyond her years, but pulsation could be felt in vessels were thickened beyond her years, but pulsation could be felt in
the anterior and posterior tibial arteries. The knee-jerks were absent; the anterior and posterior tibial arteries. The knee-jerks were absent; otherwise there were no symptoms of disease of the central nervous
system. The urine, which averaged 50 ounces per diem, contained albumin and sugar (1800 grains daily). On standing it became dark green, and the distillate gave the carbolic acid tests. The patient wa placed upon a modified diet; the foot was incised on several occasions
under local anæsthesia and treated with baths and dry dressings. The under local anæsthesia and treated with baths and dry dressings. The
cellulitis subsided, the general condition became much better, the carboluria rapidly disappeared, and the daily excretion of sugar gradually fell to 120 grains. In three weeks time, however, the gangrenous process began to spread and amputation was
advised. On March 9th this was performed by lateral flaps at the junction of the middle and the lower thirds of leg (somewhat unwisely though at the importunity of the friends). Perfect anæsthesia was rapidly obtained by the above method; no discomfort was experienced; the pulse-rate at the beginning of the operation was 140, at the end 120. (Previous to operation her pulse-rate varied between 100 and 120.) The tibial arteries were rigid and calcareous and the flaps became necrotic. There was no attempt at repair, so re-amputation was per-
formed on March 22 nd at the junction of the middle and the lower thirds of the thigh, spinal anæsthesia being used. Recovery was uneventful, the daily exeretion of sugar had on a rigid diet dropped to nil. and the patient left the hospital on April 2lst.

CASE 7.-A female, aged 58 years, was admitted to hospital on six plantar aspect, sinuses, at the bottom of which on the dorsal and the plantar aspect, sinuses, at the bottom of which bare bone could be felt artery. The patient had polyuria and the urine contained much artery. The patient had polyuria and the urine contained much albumin and sugar (average daily excretion 3000 grains). The temperature reached $101^{\circ} \mathrm{F}$., the gangrenous process continued to spread, and third of the thigh was performed on March 23 rd. Venous anæsthesia was used (in this case 200 cubic centimetres of a 0.25 per cent. solution of novocaine); the patient was highly nervous, so a preliminary injection of a quarter of a grain of morphia was given. Owing to the condition of the tissues the Esmarch's bandage was applied entirely above the septic area; this produced pain in the foot, and chloroform inhala-
tion became necessary until indirect anrsthesia was established. the patient was perfectly conscious, however, for the division of The patient was perfectly conscious, however, for the division of period. The pulse-rate before operation was 88 , at the end 90 . Unfortonately, the heart began to fail two days later and the patient died on March 28th.

Necropsy.- The heart was soft, large, and dilated (especially the were large and pale. The amputation wound showed no attempt at

CASE 8.-A male, aged 58 years, was admitted to hospital for gangrene of the right foot, which started a month before admission. During the previous eight months he had been under treatment for diabetes in the out-patient department; he had also attended an eye hospital, where he was told he had "diabetic hæmorrhages in his disc." On admission there were redness and cedema extending on to the dorsum and the sole of the involved foot. There was practically no pain; pulsation could be felt in both anterior and posterior tibial arteries. There was no lesion of the heart, nor did his vessels appear to be thickened beyond hi years. The knee-jerk on the right side was obtained with difficulty;
on the left side it was absent. The urine, which averaged 65 ounces daily, contained albumin and sugar; the daily excretion of 65 ounces daily, contained albumin and sugar; the daily excretion of the latter was 1100 grains. With rest and a modified diet the cellulitis subsided and the daily excretion of sugar dropped to 90 grains. For
nearly a week the patient continued to improve, but then the gangrenous process began to spread and he suffered much pain. On April 7th amputation was performed by venous anæsthesia, 150 cubic centimetres of 0.5 per cent. novocaine solution being used. The patient's nutrition and vascular system seemed so good that it was decided to amputate at the seat of election. Good anæsthesia was obtained, but he had a twinge of pain as the anterior tibial nerve was divided. There were no alteration in the pulse-rate and no shock.
Unfortunately, bæmorrhage from the stump occurred on the sixth day. The wound was opened up and the bleeding posterior tibial artery was secured. There was no attempt at repair and the flaps had commenced to slough. The patient did not recover sufficiently to make

Necropsy. - The aorta showed patches of atheroma. The heart was slightly enlarged and the mitral and aortic valves showed early sclerotic changes. The popliteal artery on the amputated side was practically normal; the posterior tibial artery was calcareous and
rigid. The kidneys were large and pale. The pancreas showed neither macroseopic nor microscopic changes.

CASE 9.-A female, aged 55 years, had been under private treatment for diabetic gangrene of her left foot for three months. On admission to hospital on July 3rd, 1909, the anterior part of this foot was foul and gangrenous. The general condition was good. The cardio-vascular anterior and posterior tibial arteries of the diseased side. The kneemuch albumin. The daily excretion of sugar was 2420 grains; on a 
modified diet this had dropped at the end of a fortnight to 1000 modified diet this had dropped at the end of a fortnight to 1000 grains. The gangrene now began to spread along the inner aspect of the foot, and the patient was having much pain. Amputation through the lower third of the thigh was therefore performed on July 18th under venous anæsthesia. A preliminary injection of a quarter of a grain of morphia was given, as the bandage had to be applied entirely above the gangrenous area. The congestion of the foot resulting from the latter procedure caused considerable pain, and the pulse-rate rose from 92 to 104 . A further injection of morphia was therefore given. Good anæsthesia was soon obtained, 150 cubic centi metres of a 0.5 per cent. solution of novocaine being used. The patient bowever, suddenly lapsed into coma before the completion of the operation. She was infused with sodium bicarbonate, \&c., but remained comatose until death, which occurred two days later.

Necropsy.-The kidneys were large and pale; the aorta was atheromatous. The pancreas and other organs showed no gross lesion.

\section{Comments.}

If the technique be carefully carried out absolute anæsthesia will in most cases be readily obtained. Professor Bier reports two cases where analgesia only was present; this, however, was of such a character that the operation could be completed without resort to general narcosis. In our own cases the local anæsthesia has been perfect except in one case involving the toes only (Case 2). Probably the cause here was failure to empty the part of blood. In this instance, however, the analgesia was sufficient for the completion of the operation. In three cases in which the Esmarch bandage had to be applied above an infective focus, pain in the foot was evoked by the resulting venous congestion. Thus in Cases 3 and 7 a small amount of chloroform was necessary for the early stage of the operation. In Case 9 an injection of morphia sufficed. In all these cases the pain passed off when "indirect" anæsthesia became established. When the Esmarch bandage can be applied to the whole of the distal portion of the limb it can be applied sufficiently tightly without causing discomfort, except perhaps in those cases where the arteries are calcareous and rigid. Failure of the upper bandage to secure hæmostasis (and as a result imperfect anæsthesia) may occur in patients whose arteries are rigid. The same difficulty may arise where the thick part of the thigh is the seat of operation; thus in one case we had to employ the ordinary tubular tourniquet, a proceeding associated with considerable discomfort.

The danger of toxic symptoms from novocaine will only arise at the moment when the upper bandage is loosened, or when perfect hæmostasis has not been obtained. In our own amputations the amount of novocaine gaining access to the general circulation has not been sufficient to alter the pulserate, except in the case of an old man (Case 3) whose arteries were extremely rigid. Obviously, toxic symptoms are less likely to occur in amputation cases (where the solution has free egress from the divided tissues) than in more limited operations. In the former cases drainage of the wound for 24 hours is advisable. Professor Bier has recorded one case in which toxic symptoms arose. 150 cubic centimetres of a 0.25 per cent. novocaine solution had been injected; 15 minutes after removal of the bandage the subject, a woman, aged 60 years, vomited, and her pulse became small and quick. She rapidly recovered, however, and had no further symptoms. In a good many of our cases some irregularity and increase in the rate of the pulse were noted on the second or the third day. This late and transitory disturbance of the cardiac system we have also seen in some cases where only 10-20 cubic centimetres of a 0.5 per cent. novocaine solution had been used for producing anæsthesia by perineural injection. Professor Bier has recommended that at the completion of the operation the upper bandage should be very gradually relaxed, thus preventing too rapid diffusion of the novocaine. He has also suggested that normal saline solution should be run through the veins in the isolated area. It might be urged as an objection to this form of anæsthesia that the technique requires too much time. In a thin subject where the vein is readily found this should not take more than 15 minutes. In fat subjects, however, it is, for this reason, inferior to spinal anæsthesia for operations on the lower limb. In the case of the upper limb, when general anæsthesia is contraindicated, it seems to us to be a method of the greatest value.

For permission to publish these cases we beg to acknowledge our indebtedness to $\mathrm{Mr}$. H. H. Olutton, Mr. W. H. Battle, Mr. O. A. Ballance, Mr. H. Betham Robinson, and Mr. E. M. Corner, under whose care the patients were admitted to hospital.

Reference.-Archiv für Klinische Chirurgie, Band 1xxxvi., 4, "Uber

\section{AN EPIDEMIC OF ENTERIC FEVER, PROBABLY DUE TO INFECTION BY A "CARRIER."}

BY HENRY ROSCOE, M.R.C.S. ENG., L.R.C.P. LOND., D.P.H. VICT.,

SENIOR ASSISTANT MEDICAL OFFICER AT CHEDDLETON COUNTY ASYLUM, STAFTS.

THERE is grave doubt whether it can ever be proved beyond all cavil that any case of enteric fever has been infected by a carrier, for the difficulties in the way of absolutely excluding every other possible source are practically insurmountable. We now know that, whether or no the bacillus typhosus ever actually spores, certain individuals do occur which have such special powers of resistance and survival for lengthened periods, that they are as dangerously long-lived as sporing bacilli ; infection may therefore lurk in unsuspected places long after its possibility has been lost sight of. On the other hand, it is almost equally difficult to prove that a probable carrier has actually infected any given case; the destructive critic could find weaknesses in any such case yet reported or likely to be reported. The following account of a slight epidemic at Cheddleton Asylum, which commenced in September, 1908, and lasted until March, 1909, justifies, in my opinion, faith in the carrier theory as an explanation. Owing to specially favourable circumstances, exclusion of other sources is almost completely possible, whilst there was on the scene a carrier who was capable of causing the mischief.

The asylum, opened in 1899, originally contained 16 wards ; eight additional wards were completed and opened in April, 1909. It was in one of these new wards, F 19, that the epidemic began. From first to last there were 12 cases, all females. Enteric fever was not diagnosed for a few days as there had been no case here for six years. During these few days the first three patients, F a, F b, and F c, were not isolated, and one of them, $F$ a, who was nursed in the sick room $\mathrm{F} 11$, was in close contact with a working patient, $\mathrm{F} \mathrm{d}$, who helped to remove slops, \&c. F a began to be ill on Sept. 26th, F b and F c on the 29th; F d was attacked on Oct. 12th, Fe on Nov. 3rd, F $f$ on the 6 th, F $g$ on the 15 th, $\mathrm{Fh}$ on the 26th, Fi on the 27th. F $\mathrm{k}$ on Jan. 12th, Fl on Feb. 3rd, and F m on March 9th.

Since the last-mentioned date up to that of writing, Oct. 1st, there has been no case resembling enteric fever, although in several instances of slight fever a Widal test has been applied with negative results. A positive reaction had been obtained in all the 12 cases noted above, with the exception of that of $\mathrm{Fi}$, who died on the tenth day of illness after perforation. Nine of the 12 cases occurred in ward $\mathrm{F} 19$, the exceptions being $\mathrm{F} \mathrm{d}, \mathrm{F} \mathrm{f}$, and $\mathrm{F} \mathrm{m}$. F d has already been accounted for; $F$ f was a refractory patient in ward $F 14$, who was dirty in habits and who required attention at night, this being supplied by a relief night nurse, somewhat inexperienced, who also attended to similar cases in F 19. Assuming for the moment that there was a carrier in $\mathrm{F} \mathrm{19}$, and that she was a patient of dirty habits who required attention at night, the connexion is obvious. As regards $F m$, there is no really satisfactory explanation. She lived in ward F 15, which is in the same block as $F 14$, and, being at times refractory, was at such times sent for short periods to $F 14$, and was so sent on several occasions about the time when she became infected. It can only be suggested that she came in contact with some infective matter which had escaped sterilisation when the ward was disinfected after F f sickened. As F m was a restless patient, with wellknown propensities for picking up and hoarding rubbish, this is a possible, if not a convincing, explanation.

It should be mentioned that all cases were, as soon as diagnosed, removed to the asylum isolation hospital, and that thorough disinfection was carried out after each case occurred. The procedure was to wash floors, walls, fixtures, furniture, \&c., with either chloros or formaldehyde solution, 1 per cent., according to the nature of the article to be disinfected, and to follow this up by spraying with formaldehyde solution, finishing up by aerial disinfection with gaseous formaldehyde, using a quantity of formalin calculated to give 0.25 per cent. of $\mathrm{HCOH}$ in the air.

It is clear that infection commenced in ward $F 19$, the inmates of which are mostly infirm old women, and which 